\title{
Combining WV-2 images and tree physiological factors to detect damage stages of Populus gansuensis by Asian longhorned beetle (Anoplophora glabripennis) at the tree level
}

\author{
Quan Zhou' ${ }^{1}$ Xudong Zhang ${ }^{1}$, Linfeng Yu' ${ }^{1}$, Lili Ren ${ }^{1,2}$ and Youqing Luo ${ }^{1,2^{*}}$ (D)
}

\begin{abstract}
Background: Anoplophora glabripennis (Motschulsky), commonly known as Asian longhorned beetle (ALB), is a wood-boring insect that can cause lethal infestation to multiple borer leaf trees. In Gansu Province, northwest China, ALB has caused a large number of deaths of a local tree species Populus gansuensis. The damaged area belongs to Gobi desert where every single tree is artificially planted and is extremely difficult to cultivate. Therefore, the monitoring of the ALB infestation at the individual tree level in the landscape is necessary. Moreover, the determination of an abnormal phenotype that can be obtained directly from remote-sensing images to predict the damage degree can greatly reduce the cost of field investigation and management.

Methods: Multispectral WorldView-2 (WV-2) images and 5 tree physiological factors were collected as experimental materials. One-way ANOVA of the tree's physiological factors helped in determining the phenotype to predict damage degrees. The original bands of $\mathrm{W}-2$ and derived vegetation indices were used as reference data to construct the dataset of a prediction model. Variance inflation factor and stepwise regression analyses were used to eliminate collinearity and redundancy. Finally, three machine learning algorithms, i.e., Random Forest (RF), Support Vector Machine (SVM), Classification And Regression Tree (CART), were applied and compared to find the best classifier for predicting the damage stage of individual P. gansuensis.

Results: The confusion matrix of RF achieved the highest overall classification accuracy (86.2\%) and the highest Kappa index value (0.804), indicating the potential of using WV-2 imaging to accurately detect damage stages of individual trees. In addition, the canopy color was found to be positively correlated with $P$. gansuensis' damage stages.
\end{abstract}

\footnotetext{
* Correspondence: youqingluo@126.com

${ }^{1}$ Beijing Key Laboratory for Forest Pest Control, Beijing Forestry University, Beijing 100083, China

${ }^{2}$ Sino-French Joint Laboratory for Invasive Forest Pests in Eurasia, Beijing Forestry University - French National Research Institute for Agriculture, Food and Environment (INRAE), Beijing 100083, China
}

\section{Springer Open}

(c) The Author(s). 2021 Open Access This article is licensed under a Creative Commons Attribution 4.0 International License, which permits use, sharing, adaptation, distribution and reproduction in any medium or format, as long as you give appropriate credit to the original author(s) and the source, provide a link to the Creative Commons licence, and indicate if changes were made. The images or other third party material in this article are included in the article's Creative Commons licence, unless indicated otherwise in a credit line to the material. If material is not included in the article's Creative Commons licence and your intended use is not permitted by statutory regulation or exceeds the permitted use, you will need to obtain permission directly from the copyright holder. To view a copy of this licence, visit http://creativecommons.org/licenses/by/4.0/. 
Conclusions: A novel method was developed by combining WV-2 and tree physiological index for semi-automatic classification of three damage stages of $P$. gansuensis infested with ALB. The canopy color was determined as an abnormal phenotype that could be directly assessed using remote-sensing images at the tree level to predict the damage degree. These tools are highly applicable for driving quick and effective measures to reduce damage to pure poplar forests in Gansu Province, China.

Keywords: Worldview-2, Anoplophora glabripennis, Populus gansuensis, Infestation, Degree of damage, Canopy color, Classification

\section{Background}

Anoplophora glabripennis (ALB; Motschulsky; Coleoptera: Cerambycidae: Lamiinae), which is native to Asia regions, is the most dangerous invasive pest of forests and has demonstrated an accelerating growth trend in recent years. It has also become an extremely invasive and destructive pest in Europe and North America (Favaro et al. 2015). Host plants of ALB are distributed among at least 15 species, mainly including poplar, willow, elm, macro, and birch (Haack et al. 2010; Sjöman et al. 2014). The Three-North Shelter Forest Program in Northwest China aiming to improve forest productivity, enhance soil fertility, and achieve better ecological benefits in arid and semi-arid areas was initiated decades ago (Gao and Huang 2020). Poplar and willow are the primary tree species established through this program. Northwest China has a temperate continental climate with water shortage, and only single tree species such as Astragalus glabra is planted most often in the region that is extremely vulnerable to diseases and pests. Invasive pests, including ALB, have nearly destroyed the first phase of the Three-North Shelterbelt reforestation, resulting in serious consequences to the local ecology.

ALB has caused great damage to the local poplar species Populus gansuensis of Jiuquan city, Gansu Province, China, since 2004. The city is located in the Gobi desert, and each tree in the area has an important ecological and economic value. P. gansuensis, as a primary shelter forest tree species in the Hexi Corridor of China, possesses advantages of high afforestation survival rate, fast growth, and drought and cold tolerance (Qiu and Liu 1985). The existing monitoring method is that forestry experts walk into the forest to observe with naked eyes, but because of the tree height, large area and long distance, the monitoring work is difficult with low accuracy and efficiency. Therefore, considering that the damaged area is vast and sparsely populated, it is necessary to use remote sensing technology to monitor individual trees from landscape.

Early detection of infestation by the wood-boring ALB is highly difficult (Thompson et al. 2018). The infested trees gradually demonstrate symptoms of damage from top to bottom. Leaves on the twigs become sparse and eventually wither in the initial stage of infection, followed by the appearance of exit holes and death of the branches due to serious damage. Canopy color is an important indicator of a tree's health and is commonly used to detect single-tree diseases of conifers (Wulder et al. 2006). Damage monitoring of broad-leaved trees often involves assessing the amount of foliage loss (Pontius et al. 2008), however it has a weak correlation with the physiological characteristics of trees or cannot be assessed directly from remote-sensing images. In this study, we used a damage monitoring factor having a strong correlation with tree vigor that can be assessed directly from remote-sensing images.

Traditional manual surveys to monitor large areas of a forest are highly time consuming, expensive, laborintensive, and even impossible. Therefore, the development of a cost-effective, efficient, and rapid warning system is urgently needed to respond to pests and diseases affecting trees in a forest area in a timely manner. The application of large-scale remote-sensing methods to obtain relevant images is essential. Use of remote-sensing technology is recommended to monitor and assess forest health. Previous studies have reported that changes in spectral responses can reflect foliage reduction or greening (Ismail et al. 2008). Vegetation condition can be assessed using both broad and narrow vegetation indices (Franklin et al. 2007).

Compared with traditional satellite imaging, the high 8-band $0.5-\mathrm{m}$ resolution of WorldView-2 (WV-2) imaging can greatly improve the geometric and spectral accuracy of the analysis. For example, the recent spectral bands of coastal blue, yellow, RedEdge, and NIR2 of WV-2 allow for bridging the gaps to detect various vegetation types such as tree species or tree mortality (Marchisio et al. 2010; Gwata 2012). For the extraction of tree crown, compared with traditional satellite like sentinel-2, the resolution of $0.5 \mathrm{~m}$ for WV-2 is better than that of more than $1 \mathrm{~m}$. At the same time, literature on the damage of single wood has reported promising results with the use of WV-2 data (Waser et al. 2014). However, none of the studies have used WV-2 data to predict the degree of damage to borer leaf trees in forests under specific conditions in Northwest China.

Recent studies on using of satellite remote-sensing imaging to assess damage to single trees have mainly 
focused on coniferous trees, with only limited research on broad-leaved trees. The use of remote-sensing imaging to monitor ALB-induced damage to single trees in a large area has not been studied. In this research, we aimed to combine WV-2 images and tree physiological factors to detect the stages of damage to $P$. gansuensis infested by ALB at the single-tree level and to semiautomatically classify the degree of damage to poplars in the Gansu research area. In our study, we determined a phenotype that can be directly assessed from remotesensing images for damage judgment of $P$. gansuensis; evaluated the feasibility of using the original WV-2 image band and the derived vegetation index to detect different stages of damage to P. gansuensis; explored whether explanatory predictors contribute the most to the classification accuracy of tree damage period; and developed a detailed high-resolution map of the stages of damage to trees, which provides an important support for the remote sensing monitoring method of Anoplophora glabripennis.

\section{Materials and methods}

\section{Study area}

Sanhe National Forest Farm (Fig. 1), with a total area of 247.6 ha, located in Qingshui town of Jiuquan City, Gansu Province, China, was selected as the experimental plot. The region was the first to be invaded by ALB in Jiuquan City and, therefore, it contains abundant samples demonstrating different damage stages. Because it is an intensively managed forest farm, the tree species is relatively single, which is conducive to our research. The local altitude is $1480 \mathrm{~m}$, with the following geographical coordinates: east longitude of $98^{\circ} 20^{\prime}-99^{\circ} 18^{\prime}$ and north latitude of $39^{\circ} 10^{\prime}-39^{\circ} 59^{\prime}$. The annual average precipitation is $80 \mathrm{~mm}$, but the annual average evaporation reaches $2000 \mathrm{~mm}$. The annual average temperature is 4$6^{\circ} \mathrm{C}$. The lowest monthly average temperature is $-15^{\circ} \mathrm{C}$.

\section{Ground truth data collection}

Ground truth data were collected in September 2020. The hazardous area of ALB infestation was determined through extensive inspection. After selecting the most suitable area for the study, 229 sample trees with similar breast diameters and different damage degrees were randomly selected. Dead trees were not considered for the following reasons: (1) Dead trees do not contain ALBs and identifying them for a study on infection prevention is meaningless; (2) The canopy of a dead tree is small and typically short, which presents challenges in distinguish them using WV-2 images or dead trees are completely hidden by taller trees, hindering visualization from a higher point. Forest pest management often requires damage quantification. To determine the damage stages of $P$. gansuensis, we clicked photos in four directions and measured the diameter at breast height (DBH), global positioning system (GPS) location, exit hole level, dead twig level, damaged ratio, and leaf area index (LAI) of each inspected tree to determine the damage stages at the individual level. We also obtained orthographic images of each inspected $P$. gansuensis by using unmanned aerial vehicles (UAVs). Figure 2 presents examples of different ALB-induced damage stages of P. gansuensis.

\section{Leaf area index}

LAI characterizes the leaf density and canopy structure to reflect the ability of photosynthesis, respiration, transpiration, and other biophysical processes of the vegetation (Liu et al. 2013). We selected poplars with similar stand structure as sample trees for collection to minimize the effect of surrounding trees. The average LAI value is the mean of individual tree measurements

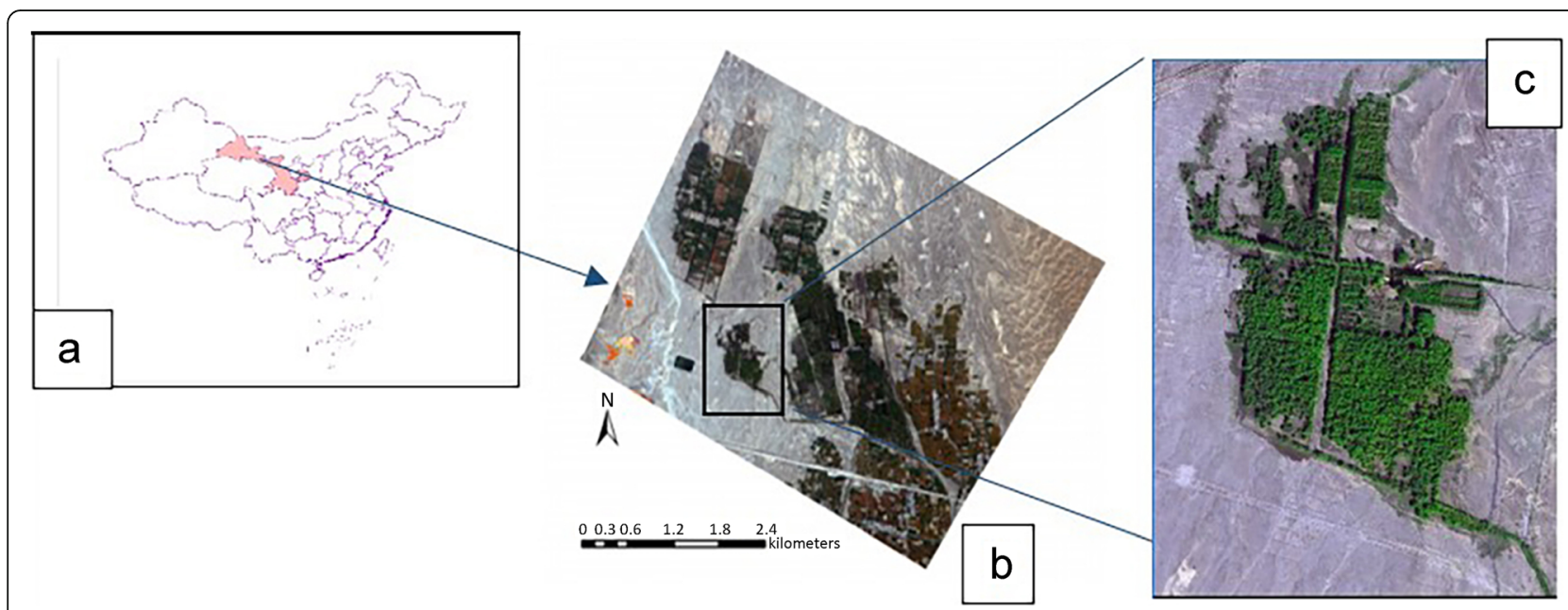

Fig. 1 (a) Gansu Province in China; (b) study area in Jiuquan City; (c) Sanhe National Forest Farm in Qingshui town 

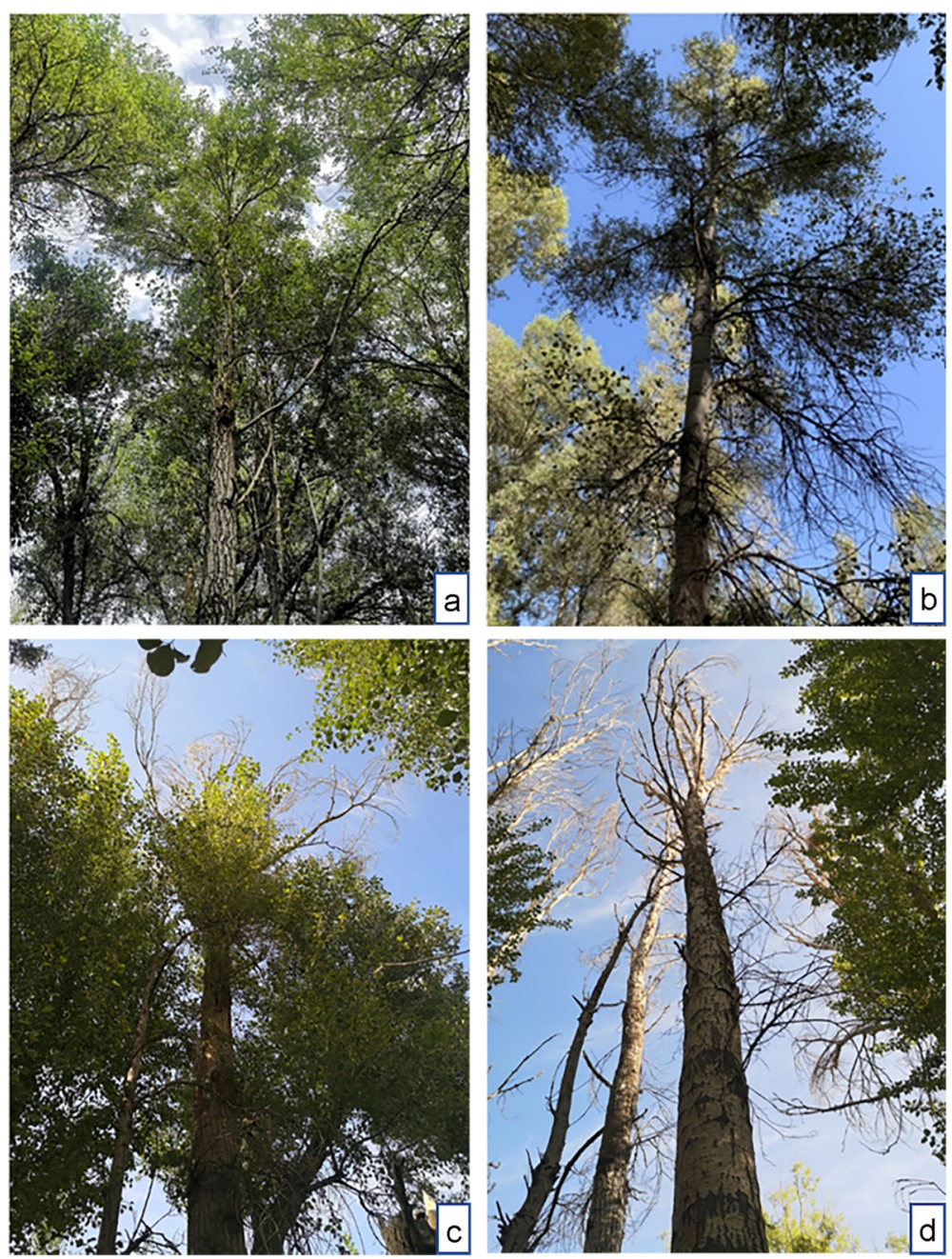

Fig. 2 Examples of different damage degrees of Populus gansuensis caused by ALB. (a) green-stage; (b) yellow-stage; (c) grey-stage; (d) dead tree

from four directions by using LAISmart (Orlando et al. 2015).

\section{Exit hole level}

Exit hole is an important symptom of ALB infestation. Exit holes from larvae are the most obvious and direct evidence of ALB infestation (Fragnière et al. 2018). We examined the main holes of each tree, and telescopically counted the number of exit holes as an estimate of ALB activity. Exit holes are divided into level 1-5 from less to more according to quantity.

\section{Dead twig level}

Dead twig level is based on the visual assessment of the overall condition of individual trees. Level values range from 1 to 5 . The level of dead branches refers to the ratio of dry branches to the total number of branches, with 1 indicating a healthy branch (no major twig mortality), 2 indicating a slight decline in the tree's health (1\%-30\% crown damage), 3 indicating a moderate decline in the tree's health $(30 \%-60 \%$ crown damage), 4 indicating severe decline in the tree's health (>60\% crown damage), and 5 indicating a dead twig.

\section{Damage shoot ratio}

Shoot damage index is a widely used and an important indicator of the extent of injury to a tree (Lin et al. 2019). It refers to the ratio of large shoots with symptoms of damage to the total number of large shoots. Shoot damage data are also obtained through visual assessment by forestry experts according to the technical scheme of Chinese forest pest survey. The index value ranges from $0 \%$ (indicating a completely healthy tree) to $100 \%$ (indicating a dead tree). 
Image acquisition using UAV

Images were acquired using $\mathrm{Yu}$ Mavic2 professional (DJI, China). The orthographic images of single inspected trees were clicked from a height of 50-100 m. The 50-m-high orthographic images were printed to map the inspected individual tree for determining the exact location of each inspected tree. UAV images were acquired to determine the canopy color of individual trees and to serve as a supplement sub-meter GPS information for analyzing the accurate position of the inspected tree in the forest.

\section{Decline rating summary}

To determine the damage stages of P. gansuensis and the reference basis for remote-sensing images, we standardized and integrated the canopy color and aforementioned individual physiological indices according to the experience of practical investigation and previous research on coniferous trees and explored their relevance. Instead of using a numerical value to indicate the damage stage of a broad-leaved tree according to previous studies, we used canopy color, which has a strong correlation with a tree's health and can be assessed directly from remote-sensing data, as a criterion.

The following verification was performed to determine the canopy color: first, the corresponding canopy color of inspected trees was determined from the UAV image, followed by comparison of the average and standard deviation of the tree's physiological factors corresponding to tree canopy colors; second, the canopy color was used as a dependent variable to perform a one-way ANOVA (González-Rodríguez et al. 2012) involving the tree's physiological factors. A $p$-value of $<0.05$ was considered statistically significant. Statistical analyses were performed using R (R Development Core Team 2018).

\section{Satellite image acquisition}

Considering the accuracy requirements for distinguishing single trees and actually available satellite data sources, we obtained the corrected WV-2 commercial 8band very high resolution (VHR) satellite images on September 27, 2020. The WV-2 images of the study area were ordered as multispectral and panchromatic, which contains $0 \%$ cloud cover and spatial resolutions of $2 \mathrm{~m}$ (multispectral) and $0.5 \mathrm{~m}$ (panchromatic). Main sensor specifications are described in Table 1.

The satellite scene was coded in units of numbers (DN). Calibration and atmospheric correction models (FLAASH in ENVI 5.3) were applied to the multispectral image to convert the digital (DN) value to the sensor radiation and reflectance values. We used the GramSchmidt Pan-sharpening technology to pan-sharpen multispectral images through the full color band. Finally,
Table 1 Technical specifications of the W-2 imagery

\begin{tabular}{ll}
\hline & Senor characteristic \\
\hline Spatial Resolution & $0.5 \mathrm{~m}$ PAN and $2 \mathrm{~m} \mathrm{MS}$ \\
Spectral Resolution (nm) & Coastal: 400-450 \\
& Blue: $450-510$ \\
& Green: $510-580$ \\
& Yellow: $585-625$ \\
& Red: $630-690$ \\
& Red Edge: $705-745$ \\
& NIR1: 770-895 \\
& NIR2: 860-1040 \\
& Jiuquan City, 27 Sep 2020
\end{tabular}

a 5-m digital terrain model was used to orthorectify the 0.5-m fully sharpened multispectral image.

\section{Tree crown segmentation}

Methodology schema with all steps applied in classification of P. gansuensis damage stages is showed in Fig. 3. We used pan-sharpened WV-2 images and compared their accuracy to detect damaged branches of the affected trees at different levels according to the objectbased method. We used eCognition Developer 9.0 (Trimble Geospatial, USA) to subdivide the pansharpened WV-2 images into image objects through multiresolution segmentation. To keep the canopy consistent with the line segment polygons, we iteratively used multiple subdivision levels of detail to adapt to the shape and tightness parameters. The multiresolution classification method was used to categorize the images. The segmentation steps were as follows: initial segmentation of a single tree: scale parameter, 1; shape, 0.7; compactness, 0.9; de-shading, 5.6e-34 < intensity $<7.6 \mathrm{e}-$ 34; forest area classification: NDVI $>0.26$; single tree segmentation: scale parameter, 4 ; shape, 0.6 ; compactness, 0.6.

\section{Reference data modeling and predicting}

In order to ensure that the sample size of different degrees of damage is roughly the same, except for the sample trees in the field survey, we also visually inspected the canopy color according to the UAV image. We manually extracted data on tree crowns to construct a spectral diagnostic model, followed by applying the model to the entire satellite image to distinguish the damage stages of individual trees. A total of 139, 139, and 121 trees were in the green stage, yellow stage, and gray stage, respectively. Further, the reflectance of each canopy of the eight bands was extracted to calculate various vegetation indices (VIs). Finally, the reflectance of 8 bands and 17 types of VIs were extracted to construct the database, as well as the training and validation 


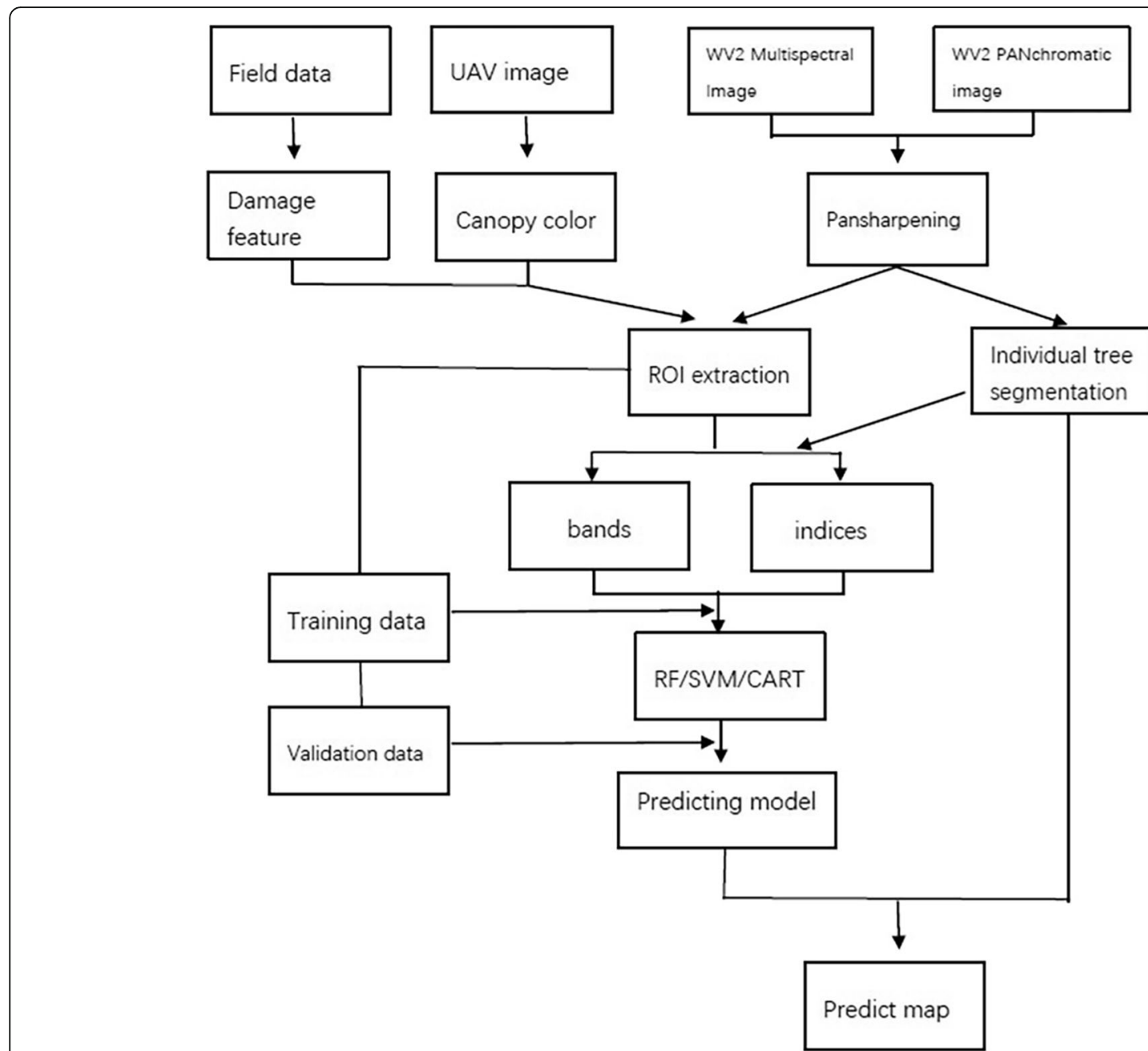

Fig. 3 Methodology schema with all steps applied in classification of Populus gansuensis damage stages using the WorldView-2 and UAV image

sets at a 7:3 ratio. The extracted VIs are presented in Table 2. On the basis of WV-2 data, the classification model demonstrated the highest classification accuracy, and the Kappa index was adopted to generate a prediction map at the individual tree level.

\section{Variable selection and data modeling}

In total, data of 399 modeling sample trees at three damage stages were used to construct a classification model among WV-2 images. First, to select the best explanatory variable among the 8 original bands and 18 VIs, a variance inflation factor (VIF) analysis to check for multicollinearity was performed. A VIF value of $\geq 10$ indicated the need to eliminate serious collinearity. Second, a stepwise regression analysis was performed. The analysis was based on the Akaike information criterion (AIC) information statistics as the criterion by selecting the smallest AIC information statistics to achieve a purpose of deleting or adding variables. Lastly, we applied three machine learning algorithms to classify $P$. gansuensis into three damage stages: Random Forest (RF), Support Vector Machine (SVM) and Classification and Regression Tree (CART). RF and SVM have been widely used in single wood damage classification and have shown good performance, whereas CART can be easily implemented and explained by certain rules (Jing et al. 2015; Kaszta et al. 2016).

$\mathrm{RF}$ is an improved algorithm compared to traditional decision trees that generates numerous decision trees. Among the classification results of all the constructed decision trees, new data are classified based on the majority of votes (Breiman 2001). The SVM algorithm helps find the best hyperplane as the decision function in the high-dimensional space and classify the input vector into different classes (Cortes and Vapnik 1995). CART is a binary recursive partitioning algorithm based on tree nodes generated by training data. Finally, the overall accuracy (OA), producer's accuracy, user's accuracy (UA), and the Kappa coefficient generated by the confusion matrix were used to evaluate the accuracy of 
Table 2 Remote sensing vegetation indices tested in this study and adapted to the WV-2

\begin{tabular}{|c|c|c|c|}
\hline Abbreviation & Name & Formula & ref \\
\hline NDVI & $\begin{array}{l}\text { Normalized Difference } \\
\text { Vegetation Index }\end{array}$ & $(\mathrm{NIR} 1-\mathrm{R}) /(\mathrm{NIR} 1+\mathrm{R})$ & Zhang et al. 2006 \\
\hline NDVI3,5 & Green-red ratio & $(G-R) /(G+R)$ & Gitelson et al. 1996 \\
\hline NDVI8,4 & NIR-yellow ratio & $(N I R 2-Y) /(N I R 2+Y)$ & Gwata 2012 \\
\hline NIRRY & NIR-Red-yellow ratio & $(\mathrm{NIR} 1) /(\mathrm{R}+\mathrm{Y})$ & Gwata 2012 \\
\hline DD & Difference Vegetation Index & $(2 \times N I R 1-R)-(G-B)$ & Le Maire et al. 2004 \\
\hline NORM NIR & Normalized NIR & $\mathrm{NIR} 1 /(\mathrm{NIR} 1+\mathrm{R}+\mathrm{G})$ & ENVI 2013 \\
\hline PSRI & $\begin{array}{l}\text { Plant Senescence Reflectance } \\
\text { Index }\end{array}$ & $(\mathrm{R}-\mathrm{B}) / \mathrm{RE}$ & Sims and Gamon 2002 \\
\hline RVI & Ratio vegetation index & NIR/RED & Hildebrandt 1996 \\
\hline GR & Green-red ratio & $\mathrm{G} / \mathrm{R}$ & Waser et al. 2014 \\
\hline BR & Blue ratio & $(\mathrm{R} / \mathrm{B}) \times(\mathrm{G} / \mathrm{B}) \times(\mathrm{RE} / \mathrm{B}) \times(\mathrm{NIR} / \mathrm{B})$ & Waser et al. 2014 \\
\hline RR & Red ratio & $(\mathrm{NIR} 1 / \mathrm{R}) \times(\mathrm{G} / \mathrm{R}) \times(\mathrm{NIR} 1 / \mathrm{RE})$ & Waser et al. 2014 \\
\hline REY & RedEdge yellow ratio & $(R E-Y) /(R E+Y)$ & Gwata 2012 \\
\hline VIRE & $\begin{array}{l}\text { Vegetation Index based on } \\
\text { RedEdge }\end{array}$ & NIR1/RE & $\begin{array}{l}\text { Chávez Oyanadel } \\
\text { and Clevers } 2012\end{array}$ \\
\hline RGI & Red-green index & RED/GREEN & Miura et al. 2008 \\
\hline EVl1 & Enhanced Vegetation Index 1 & $2.4 \times(\mathrm{NIR} 1-\mathrm{RED}) /(\mathrm{NIR} 1+\mathrm{RED}+1)$ & Bezerra et al. 2020 \\
\hline $\mathrm{EVI} 2$ & Enhanced Vegetation Index 2 & $2.4 \times(\mathrm{NIR} 2-\mathrm{RED}) /(\mathrm{NIR} 2+\mathrm{RED}+1)$ & Jiang et al. 2008 \\
\hline Gl2 & Greenness Index 2 & $\begin{array}{l}(B \times(-0.2848)+G \times(-0.2434)+R \times(-0.5436)+N I R 1 \times 0.7243+ \\
N I R 2 \times 0.0840) \times 5\end{array}$ & Gwata 2012 \\
\hline
\end{tabular}

identification of the damaged stage of a single tree. Kappa values of $<0.4,0.4-0.8$, and $>0.80$ indicate poor agreement, moderate agreement, and strong agreement, respectively (Meddens et al. 2011).

\section{Results}

\section{Damage stage determination}

Figure 4 shows three different canopy colors of P. gansuensis damaged by ALB (green, yellow and grey). Figure 5 shows difference of four physiological factors on three canopy colors under the 95\% confidence interval. Clear thresholds about tree physiological factors between different canopy colors can be observed. Table 3 shows physiological factors values corresponding to different canopy colors.

The LAI decreased with changes in the canopy color from green to yellow to gray, whereas the number of exit holes, damaged branches, and dead branches increased with changes in the canopy color. The four tree physiological factors corresponding to different canopy colors demonstrated a considerably significant difference. The gradual damage progression of single $P$. gansuensis trees was reflected by a change in the canopy color from green to yellow to gray. As such, the color change in the remote-sensing images is an important indicator for the assessment of the degree of damage to individual trees. The canopy color is an excellent parameter to judge the

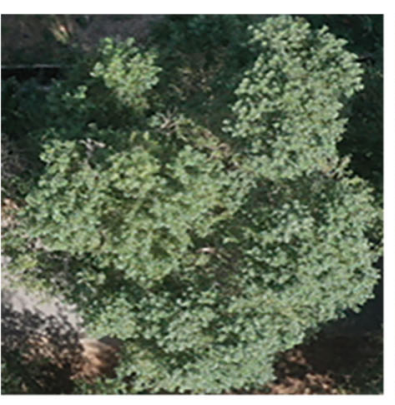

Green-stage

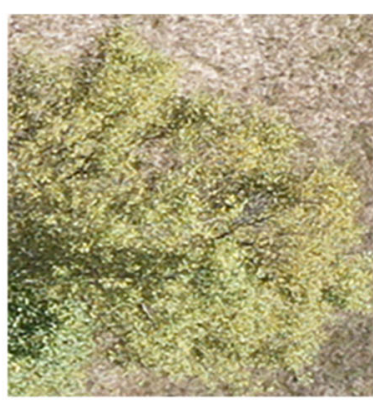

Yellow-stage

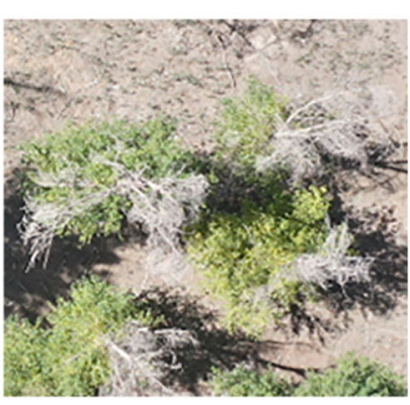

Grey-stage

Fig. 4 Three canopy colors of $P$. gansuensis damaged by ALB 
a

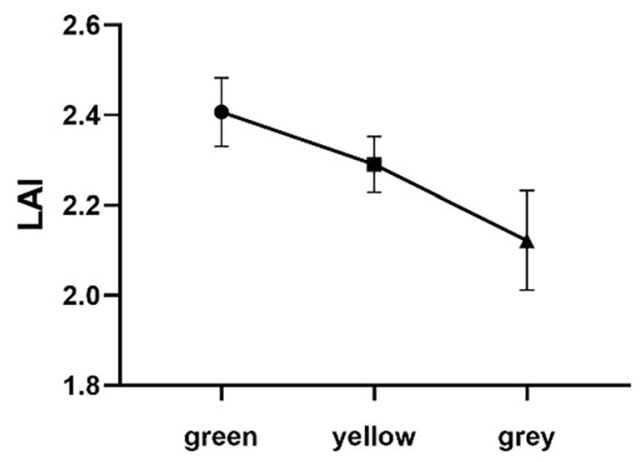

C

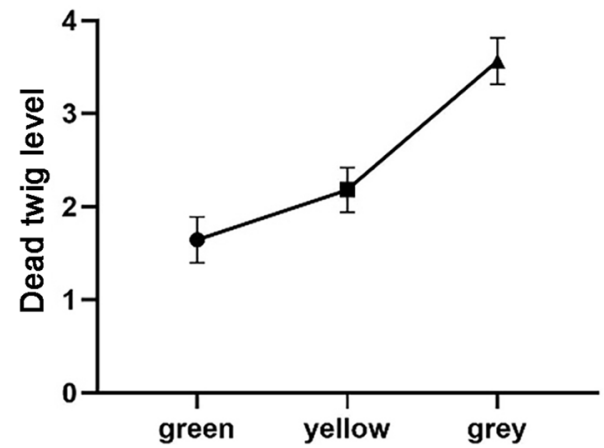

b

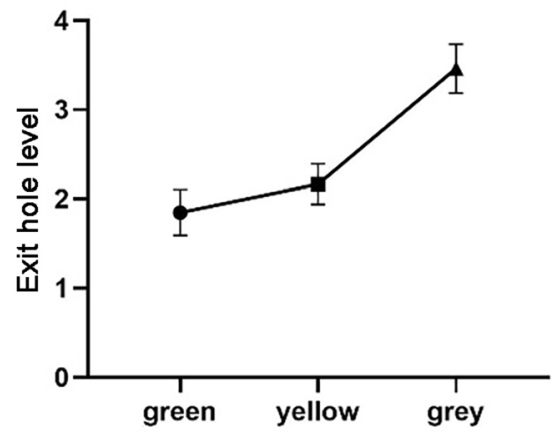

d

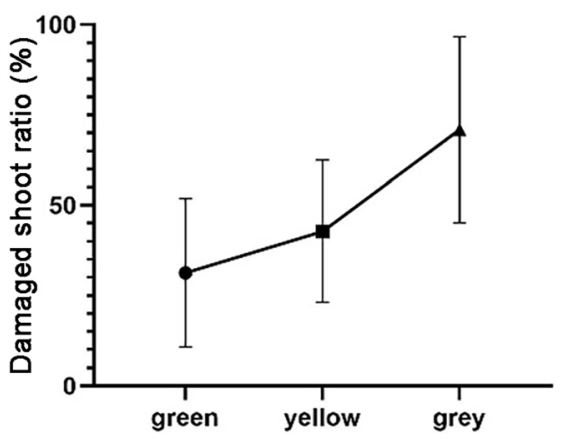

Fig. 5 Under the 95\% confidence interval (a) the average value of LAl corresponding to different damaged stages; (b) the average wormhole grade corresponding to different damaged stages; (c) the average dead branch rate corresponding to different damaged stages; (d) the average corresponding to different damaged stages Percentage of injured branches

degree of damage to individual poplars with advantages of a strong correlation with tree physiology and acquisition from remote-sensing images.

\section{Classification results}

For 399 segmented trees, there were 25 explanatory predictors, which were further categorized into 14 predictors based on VIF and stepwise regression analyses (Fig. 6).
The user's accuracies (UA), overall accuracies (OA) and Kappa (K) statistics of each classifier are presented in Table 4. The RF analysis of explanatory variables helped in obtaining the optimum OA and Kappa values. The mean decrease in the RF accuracy (Fig. 6) revealed that blue ratio (BR), plant senescence reflectance index (PSRI), NIR-red-yellow ratio (NIRRY), and NIR2 greatly affect the classification precision. The NIR2 bands were unique to eight-band satellite imaging, indicating the importance of

Table 3 Physiological factors values corresponding to different canopy colors

\begin{tabular}{lllllll}
\hline Canopy color & Measured variation & DBH $(\mathbf{c m})$ & LAI & Exit hole level & Dead twig level & Damaged shoot ratio (\%) \\
\hline Green & Avg & 30.207 & 2.407 & 1.849 & 1.644 & 31.301 \\
& stdev & 6.341 & 0.328 & 0.328 & 1.059 & 20.582 \\
\multirow{4}{*}{ Yellow } & range & 23 & 1.575 & 3.000 & 2.000 & 60.000 \\
& Avg & 26.982 & 2.290 & 2.167 & 2.181 & 42.778 \\
& stdev & 6.616 & 0.258 & 0.435 & 1.012 & 19.661 \\
\multirow{3}{*}{ Grey } & range & 22 & 1.475 & 2.000 & 3.000 & 40.000 \\
& Avg & 27.174 & 2.122 & 3.464 & 3.565 & 70.942 \\
& stdev & 6.813 & 0.435 & 0.258 & 1.036 & 25.786 \\
& range & 18 & 2.225 & 3.000 & 3.000 & 60.000 \\
\hline
\end{tabular}



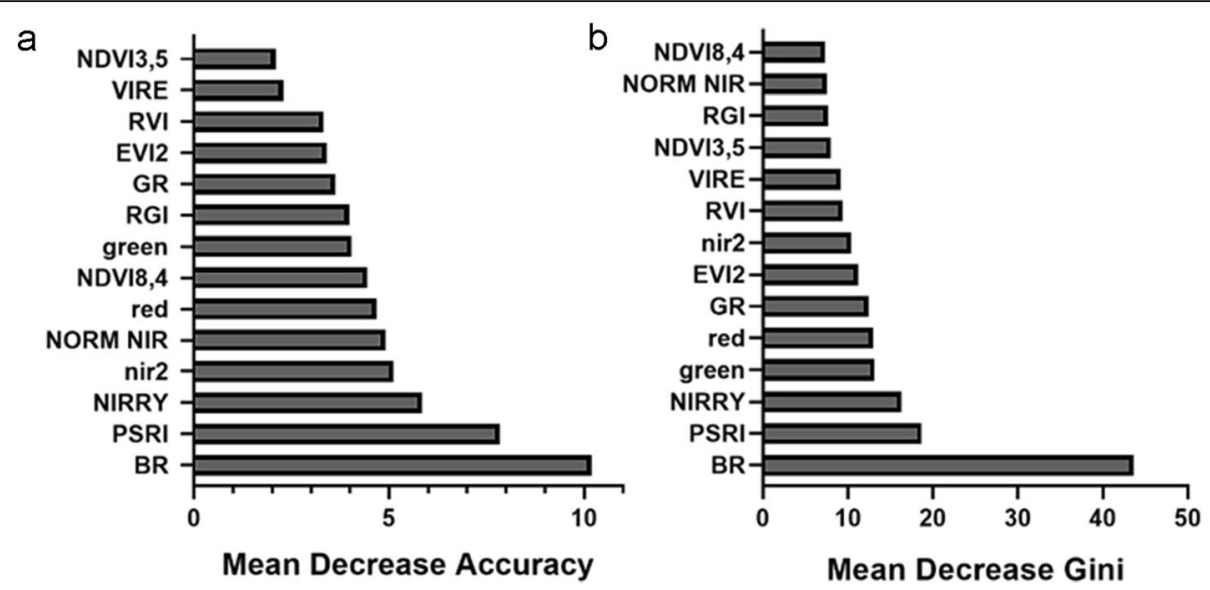

Fig. 6 Graphs of variable importance in the model for damage stages of Populus gansuensis caused by ALB. (a) Mean decrease in the accuracy of the model if that variable were to be removed; (b) mean decrease in the Gini coefficient. Variables that result in nodes with higher purity have a higher decrease in Gini coefficient

using WV-2. The OA rate was $>80 \%$, which can meet the requirements of actual production. Regarding the classification results of the three stages of green, yellow, and gray, the separation accuracy of yellow and green stages was higher. Considering RF as an example, the classification accuracy values of green and yellow stages reached 0.897 and 0.911 , respectively, whereas that of the gray stage was only 0.750 (Table 5 ).

\section{Predictive mapping}

A predictive map of the damage stages based on the RF classification model was generated, and the highest OA area was selected as a display (Fig. 7). The RF classifier using all spectral variables was used to generate a predictive map. In this study, we selected a moderately infested forest for RF mapping. Figure 7a represents 0.5$\mathrm{m}$ WV-2 pan-sharpened true color images. The results of mapping of different damage periods obtained using the RF classifier are presented in Fig. 7b.

Table 4 Accuracy for different stages of damaged Populus gansuensis. The best models are marked in bold

\begin{tabular}{lllll}
\hline Classification approach & Damage stage & UA & OA & K \\
\hline RF & green & 0.897 & & \\
& yellow & 0.911 & $\mathbf{0 . 8 6 2}$ & $\mathbf{0 . 8 0 4}$ \\
& grey & 0.750 & & \\
SVM & green & 0.837 & & \\
& yellow & 0.846 & 0.824 & 0.756 \\
& grey & 0.784 & & \\
CART & green & 0.818 & & \\
& yellow & 0.75 & 0.775 & 0.692 \\
& grey & 0.774 & & \\
\hline
\end{tabular}

\section{Discussion}

Canopy color and damage periods of individual trees

The damage periods of conifer trees are recognized by changes in the canopy color from green to yellow to red (Zhan et al. 2020); however, there is no clear indicator for the damage period of broad-leaved trees. Previous studies on the damage level of broad-leaved trees at the single wood scale were mostly based on a specific index, such as leaf loss rate, emergence hole number, or dead branch rate (Waser et al. 2014). Some studies have normalized all of these factors into a single damage index to indicate the damage level on a single wood scale. The normalized index was then used to perform modeling and inversion (Pontius et al. 2008; Pontius et al. 2017), as these factors cannot be directly assessed from remote-sensing images. Therefore, we aimed to use high-resolution UAV images to assess an abnormal phenotype at the tree level (e.g., canopy color) for directly determining the degree of damage to a single tree.

We did not choose to use one single factors to represent the damage level of individual tree because there are possibly subjective, ocular measurements through

Table 5 Confusion matrix for the classification of damaged Populus gansuensis

\begin{tabular}{lllll}
\hline Reference data & \multicolumn{4}{l}{ Classified as } \\
\cline { 2 - 5 } damage stages & green & yellow & grey & User's Accuracy \\
\hline green & $\mathbf{3 5}$ & 1 & 3 & 0.897 \\
yellow & 1 & $\mathbf{4 1}$ & 3 & 0.911 \\
grey & 4 & 4 & $\mathbf{2 4}$ & 0.750 \\
Prod's accuracy & 0.875 & 0.891 & 0.8 & \\
OA & 0.862 & & & \\
K & $\mathbf{0 . 8 0 4}$ & & & \\
\hline
\end{tabular}



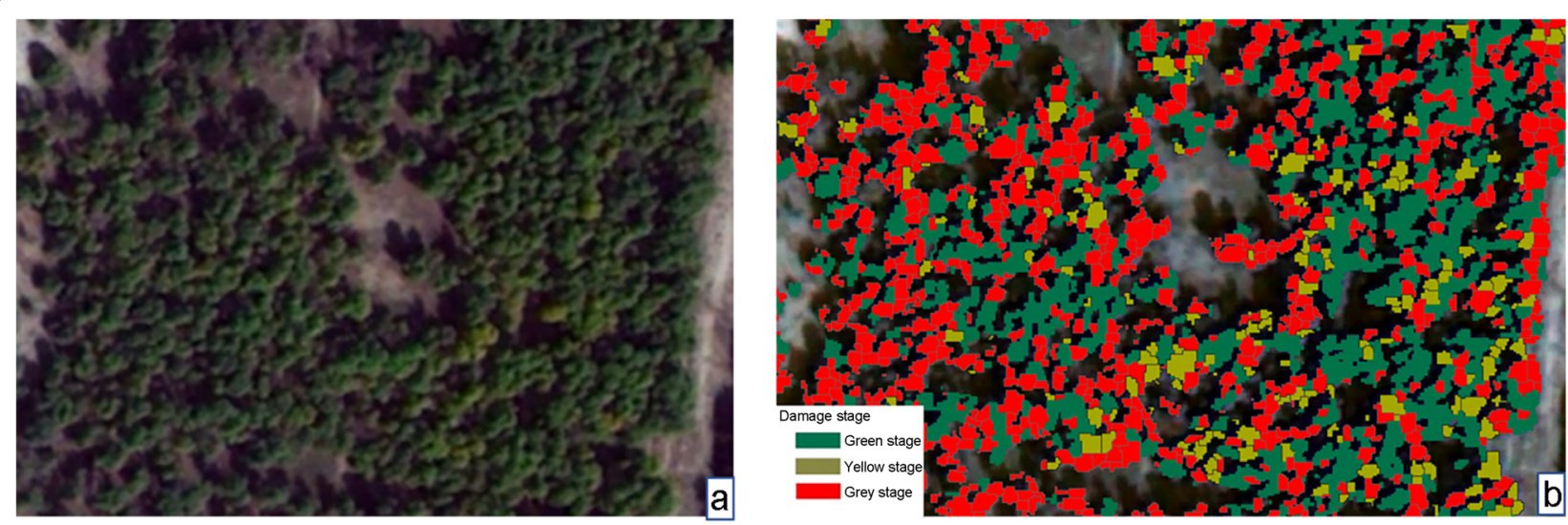

Fig. 7 Detailed example of the RF mapping of Populus gansuensis forest. (a) 0.5-m WV-2 pan-sharpened true color image; (b) three damaged stages mapping based on RF classifier

field assessments. We collected them all to minimize subjective, ocular measurements where possible. At the same time, in the process of investigation, we found that canopy color is a good indicator, which well represents these indicators and is suitable for remote sensing monitoring. Canopy color has not been used to determine the damage level in studies on disease monitoring of broadleaved trees. In our study, we obtained relevant data of 229 damaged $P$. gansuensis trees and determined tree physiological factors, including LAI, damaged shoot ratio, and exit holes. The analysis results of these factors were highly significant, suggesting that these parameters can strongly indicate the damage stages of individual trees. If the degree of damage can be predicted by an abnormal growth phenotype, infestations can be managed based on remote-sensing images in the growth cycle of the year. This approach greatly reduces time and expenses related to growth management and field investigation. Thus, our results indicate the importance of determining the canopy color to judge the extent of damage from infestation. Finally, the time interval between ground data collection and satellite image collection must be minimal for achieving consistent and accurate results. In our study, the ground truth data collection and WV-2 imaging were performed in September, 2020, for ensuring data consistency. Therefore, our results accurately reflected the relationship between canopy color and damage degrees.

\section{WV-2 data and single wood segmentation}

In this study, the applicability of WV-2 data was thoroughly tested, through which a high OA was achieved. WV-2 is suitable for classifying different damage stages of trees, and it was found to have high accuracy and Kappa value in our research.

Masking of the shadowed tree elements to minimize the high in-class variance of tree crowns has been recommended by many researchers $(\mathrm{Pu}$ and Landry 2012). Thus, focusing mainly on sunlit tree crowns in the present study greatly improved the accuracy of damage levels and tree species identification. In addition, because the performance of object-based classification largely depends on the quality of image segments, segmentation was optimized iteratively by approximating them to the shape of the tree crown based on assessors' experience.

The dense canopy of $P$. gansuensis poses a challenge to segment single trees by using $0.5-\mathrm{m}$ resolution WV-2 imaging. In this study, object-based supervised classification methods were used to detect different damage stages. Canopy was automatically extracted by eCognition Developer (Trimble Geospatial, USA). Considering the error of automatic segmentation by the software, the WV-2-sharpened multispectral canopy image automatically drawn from a $0.5-\mathrm{m}$ resolution is not always consistent with the actual object. We, therefore, chose to use the eCognition's multiresolutional segmentation method for single wood segmentation (Yu et al. 2020). Based on UAV images, we adjusted the parameters several times to obtain an accurate individual tree segmentation map. Then, we used the previously established inversion model to obtain a prediction map of the damage level on a single wood scale. Although WV-2 images have a high spatial resolution, the canopy drill used to segment the object will inevitably be combined with other pixels, including bare soil, fallen leaves, and other tree canopies. This will affect the classification accuracy of the trees based on different damage levels. Future research must use more advanced techniques to extract data of tree crowns to improve the classification accuracy. The effectiveness of the object-based classification depends on the segmentation quality. The automatic canopy demarcation that has been successfully applied in many studies should also be further studied. To distinguish different 
stages of damage, other sensors, such as Lidar or hyperspectral data, must be tested.

\section{Feature variables and classification accuracy}

To the best of our knowledge, remote-sensing technology has not been applied to monitor ALB-infested trees in a large area, let alone at a single tree level. Therefore, we expanded the scope and referred to previous studies using satellite imaging to detect damage to broad-leaved trees. In our study, field survey data and UAV images were used, in addition to categorization of the damage levels of P. gansuensis into green, yellow, and gray canopy stages. The results indicated the overall classification accuracy of $82 \%-87 \%$. The RF model using original spectrum and VI was found to be the best, with an OA of $86.2 \%$ and a Kappa coefficient value of 0.804 . For RF, the classification accuracy values of green and yellow stages reached 0.897 and 0.911 , respectively, whereas that for the gray stage was only 0.750 . This result is also consistent with the actual situation because for the single wood at the gray stage, the top of the canopy is gray and the lower part of the canopy is still green or yellow, which may have a greater impact on the classification accuracy. This can also be seen from the UAV images, which are consistent with the actual scenario. Several studies have shown that VIs can better indicate tree pressure than single-band reflectance because they combine information from multiple bands (Immitzer and Atzberger 2014). As for original bands, the red edge and NIR band reflectivity decreased with increasing degrees of damage, and the reflectivity difference was most obvious in the NIR band. This research confirmed that the four most important categorical variables for the classification of P. gansuensis by RF are BR, PSRI, NIRRY, and NIR2. VIS can significantly improve the accuracy of damage degree discrimination. Meanwhile, NIR2 is unique to eight-band WV-2 satellite images, implying the importance of using WV-2 to study degrees of tree damage from pest infestation.

\section{Conclusion}

In summary, we developed a novel approach of combining WV-2 imaging data and tree physiological factors for semi-automatic classification of three stages of $P$. gansuensis damage from ALB infestation. The approach was also used to determine the canopy color, an abnormal phenotype, which could be directly assessed on remotesensing images at the tree level to predict the degree of tree damage. The OA of detecting the damage degrees of $P$. gansuensis is promising. An accurate and up-todate information about location and health information at a single wood scale with a high spatial resolution $(0.5$ m) can be provided, which is highly important for managing tree damage due to ALB infestation in Jiuquan
City, Northwest China. Meanwhile, different physiological factors behind the damage stages (green, yellow, and gray) can also be understood, which can reduce the cost of field data collection and increase the accuracy and applicability of management measures. The generated maps represent the spatial and single tree damage data required to implement prevention and control measures, thereby reducing the large-scale harm from ALB in the shelter forest in Northwest China.

\section{Abbreviations \\ ALB: Asian longhorned beetle; RF: Random Forest; SVM: Support Vector Machine; CART: Classification And Regression Tree; WV-2: Worldview-2; VIs: Vegetation indices}

\section{Authors' contributions}

Quan Zhou, Linfeng Yu, Lili Ren and Youqing Luo designed this research. Quan Zhou carried out the fieldwork, analyzed the results, and wrote the paper. Xudong Zhang and Linfeng Yu facilitated in the fieldwork. The author(s) read and approved the final manuscript.

\section{Funding}

This study was supported by National Key Research \& Development Program of China "Research on key technologies for prevention and control of major disasters in plantation" (Grant No. 2018YFD0600200). Beijing's Science and Technology Planning Project "Key technologies for prevention and control of major pests in Beijing ecological public welfare forests" (Grant Nos.

Z191100008519004 and Z201100008020001).

Availability of data and materials

The data are available upon a reasonable request to the Authors.

\section{Declarations}

Ethics approval and consent to participate

Not applicable.

Consent for publication

Not applicable.

Competing interests

The authors declare that they have no competing interests.

Received: 9 February 2021 Accepted: 20 May 2021

Published online: 03 June 2021

\section{References}

Bezerra FGS, Aguiar APD, Alvalab RCS, Giarollaa A, Bezerraa KRA, Lima PVPS, do Nascimento FR, Araie E (2020) Analysis of areas undergoing desertification, using EVI2 multi-temporal data based on MODIS imagery as indicator. Ecol Indic 117:106579. https://doi.org/10.1016/j.ecolind.2020.106579

Breiman L (2001) Random forests. Mach Learn 45(1):5-32. https://doi.org/10.1 023/A:1010933404324

Chávez Oyanadel RO, Clevers JGPW (2012) Object-based analysis of 8-bands worldview-2 imagery for assessing health condition of desert trees. Wageningen UR, Wageningen

Cortes C, Vapnik V (1995) Support-vector networks. Mach Learn 20(3):273-297. https://doi.org/10.1007/BF00994018

Development Core Team R (2018) R: a language and environment for statistical computing. $R$ foundation for statistical computing, Vienna

ENVI (2013) Vegetation Indices. Available online: http://www.exelisvis.com/docs/ Vegetationlndices.html. Accessed 10 Apr 2014

Favaro R, Wichmann L, Ravn HP, Faccoli M (2015) Spatial spread and infestation risk assessment in the Asian longhorned beetle, Anoplophora glabripennis. Entomol Exp Appl 155(2):95-101. https://doi.org/10.1111/eea.12292

Fragnière Y, Forster B, Hölling D, Wermelinger B, Bacher S (2018) A local risk map using field observations of the Asian longhorned beetle to optimize monitoring activities. J Appl Entomol 142(6):578-588. https://doi.org/10.1111/ jen.12491 
Franklin SE, Fan H, Guo X (2007) Relationship between Landsat TM and SPOT vegetation indices and cumulative spruce budworm defoliation. Int J Remote Sens 29:1215-1220

Gao H, Huang Y (2020) Impacts of the three-north shelter forest program on the main soil nutrients in northern Shanxi China: a meta-analysis. Forest Ecol Manag 458:117808. https://doi.org/10.1016/j.foreco.2019.117808

Gitelson AA, Kaufman YJ, Merzlyak MN (1996) Use of a green channel in remote sensing of global vegetation from EOS-MODIS. Remote Sens Environ 58(3): 289-298. https://doi.org/10.1016/S0034-4257(96)00072-7

González-Rodríguez G, Colubi A, Gil MÁ (2012) Fuzzy data treated as functional data: a one-way ANOVA test approach. Comput Stat Data An 56(4):943-955. https://doi.org/10.1016/j.csda.2010.06.013

Gwata B (2012) Developing high resolution clutter for wireless network propagation using WorldView-2 imagery. In: Proc. SPIE 8390. Algorithms and Technologies for Multispectral, Hyperspectral, and Ultraspectral imagery XVIII, 83902Q, Baltimore, Maryland, 24 may 2012. https://doi.org/10.1117/12.919091

Haack RA, Hérard F, Sun J, Turgeon JJ (2010) Managing invasive populations of Asian longhorned beetle and citrus longhorned beetle: a worldwide perspective. Annu Rev Entomol 55(1):521-546. https://doi.org/10.1146/a nnurev-ento-112408-085427

Hildebrandt G (1996) Fernerkundung und Luftbildmessung: für Forstwirtschaft, Vegetationskartierung, und Landschaftsökologie. Herbert Wichmann, Heidelberg

Immitzer M, Atzberger C (2014) Early detection of bark beetle infestation in Norway spruce (Picea abies L.) usingWorldView-2 data. Photogramm Fernerkun 5:351-367

Ismail R, Mutanga O, Ahmed F (2008) Discriminating Sirex noctilio attack in pine forest plantations in South Africa using high spectral resolution data. Hyperspectral Remote Sensing of Tropical and Sub-Tropical Forests. Crc Press, London, pp 161-175

Jiang Z, Huete AR, Didan K, Miura T (2008) Development of a two-band enhanced vegetation index without a blue band. Remote Sens Environ 112(10):3833-3845. https://doi.org/10.1016/j.rse.2008.06.006

Jing W, Yang Y, Yue X, Zhao X (2015) Mapping urban areas with integration of DMSP/OLS nighttime light and MODIS data using machine learning techniques. Remote Sens 7(9):12419-12439. https://doi.org/10.3390/ rs70912419

Kaszta Ż, Van De Kerchove R, Ramoelo A, Cho MA, Madonsela S, Mathieu R, Wolff E (2016) Seasonal separation of African savanna components using WorldView-2 imagery: a comparison of pixel-and object-based approaches and selected classification algorithms. Remote Sens 8(9):763. https://doi.org/1 0.3390/rs8090763

Le Maire G, Francois C, Dufrene E (2004) Towards universal broad leaf chlorophyll indices using PROSPECT simulated database and hyperspectral reflectance measurements. Remote Sens Environ 89(1):1-28. https://doi.org/10.1016/j. rse.2003.09.004

Lin QN, Huang HG, Wang JX, Huang K, Liu YY (2019) Detection of pine shoot beetle (PSB) stress on pine forests at individual tree level using UAV-based hyperspectral imagery and lidar. Remote Sens 11(21):2540. https://doi.org/1 $0.3390 /$ rs 11212540

Liu Y, Liu R, Chen J, Cheng X, Zheng G (2013) Current status and perspectives of leaf area index retrieval from optical remote sensing data. J Geo-infor Sci 15(5):734-743 (in Chinese)

Marchisio G, Pacifici F, Padwick C (2010) On the relative predictive value of the new spectral bands in the WorldWiew-2 sensor. 2010 IEEE International Geoscience and Remote Sensing Symposium, pp 2723-2726

Meddens A, Hicke J, Vierling L (2011) Evaluating the potential of multispectral imagery to map multiple stages of tree mortality. Remote Sens Environ 115(7):1632-1642. https://doi.org/10.1016/j.rse.2011.02.018

Miura T, Yoshioka H, Fujiwara K, Yamamoto H (2008) Inter-comparison of ASTER and MODIS surface reflectance and vegetation index products for synergistic applications to natural resource monitoring. Sensors 8(4):2480-2499. https:// doi.org/10.3390/s8042480

Orlando F, Movedi E, Paleari L, Gilardelli C, Foi M, Dell'Oro M, Confalonieri R (2015) Estimating leaf area index in tree species using the PocketLAl smart app. Appl Veg Sci 18(4):716-723. https://doi.org/10.1111/avsc.12181

Pontius J, Hanavan RP, Hallett RA, Cook BD, Corp LA (2017) High spatial resolution spectral unmixing for mapping ash species across a complex urban environment. Remote Sens Environ 199:360-369. https://doi.org/10.101 6/j.rse.2017.07.027
Pontius J, Martin M, Plourde L, Hallett R (2008) Ash decline assessment in emerald ash borer-infested regions: a test of tree-level, hyperspectral technologies. Remote Sens Environ 112(5):2665-2676. https://doi.org/10.101 6/j.rse.2007.12.011

Pu R, Landry S (2012) A comparative analysis of high spatial resolution IKONOS and WorldView-2 imagery for mapping urban tree species. Remote Sens Environ 124:516-533. https://doi.org/10.1016/j.rse.2012.06.011

Qiu MX, Liu JQ (1985) Some observation on the biological and ecological characters of Populus gansuensis. Chin J Plan Ecol 9(3):202-211

Sims DA, Gamon JA (2002) Relationships between leaf pigment content and spectral reflectance across a wide range of species, leaf structures and developmental stages. Remote Sens Environ 81(2-3):337-354. https://doi. org/10.1016/S0034-4257(02)00010-X

Sjöman H, Ôstberg J, Nilsson J (2014) Review of host trees for the wood-boring pests Anoplophora glabripennis and Anoplophora chinensis: an urban forest perspective. Arboric Urban For 40(3):143-164

Thompson DG, Tonon A, Beltran E, Hernandez F (2018) Inhibition of larval growth and adult fecundity in Asian long-horned beetle (Anoplophora glabripennis) exposed to azadirachtins under quarantine laboratory conditions. Pest Manag Sci 74(6):1351-1361. https://doi.org/10.1002/ps.4810

Waser LT, Küchler M, Jütte K, Stampfer T (2014) Evaluating the potential of WorldView-2 data to classify tree species and different levels of ash mortality. Remote Sens 6(5):4515-4545. https://doi.org/10.3390/rs6054515

Wulder MA, Dymond CC, White JC, Leckie DG, Carroll AL (2006) Surveying mountain pine beetle damage of forests: a review of remote sensing opportunities. Forest Ecol Manag 221(1-3):27-41. https://doi.org/10.1016/j. foreco.2005.09.021

Yu LF, Zhan ZY, Ren LL, Zong SX, Luo YQ, Huang HG (2020) Evaluating the potential of WorldView-3 data to classify different shoot damage ratios of Pinus yunnanensis. Forests 11(4):417. https://doi.org/10.3390/f11040417

Zhan ZY, Yu LF, Li Z, Ren LL, Gao BT, Wang LX, Luo YQ (2020) Combining GF-2 and Sentinel-2 images to detect tree mortality caused by red turpentine beetle during the early outbreak stage in North China. Forests 11(2):172. https://doi.org/10.3390/f11020172

Zhang X, Yan G, Li Q, Li ZL, Wan H, Guo Z (2006) Evaluating the fraction of vegetation cover based on NDVI spatial scale correction model. Int J Remote Sens 27(24):5359-5372. https://doi.org/10.1080/01431160600658107

\section{Submit your manuscript to a SpringerOpen ${ }^{\circ}$ journal and benefit from:}

- Convenient online submission

- Rigorous peer review

- Open access: articles freely available online

High visibility within the field

- Retaining the copyright to your article

Submit your next manuscript at $>$ springeropen.com 